\title{
Corrigendum to "Chemokines sound the alarmin: The role of atypical chemokine receptors in inflammation and cancer" [Semin. Immunol. 38 (2018) 63-71]
}

\author{
Elena Monica Borroni ${ }^{\mathrm{a}, \mathrm{b}}$, Benedetta Savino ${ }^{\mathrm{a}, \mathrm{b}}$, Raffaella Bonecchi ${ }^{\mathrm{a}, \mathrm{c}}$, Massimo Locati ${ }^{\mathrm{a}, \mathrm{b}, *}$ \\ ${ }^{a}$ Humanitas Clinical and Research Center, Via Manzoni 113, I-20089 Rozzano, Italy \\ ${ }^{\mathrm{b}}$ Department of Medical Biotechnologies and Translational Medicine, Università degli Studi di Milano, Via fratelli Cervi, I-20090 Segrate, Italy \\ ${ }^{\mathrm{c}}$ Department of Biomedical Sciences, Humanitas University, via Rita Levi Montalcini 4, I-20089 Pieve Emanuele, Italy
}

The title of this article should read as 'Chemokines sound the alarmin: The role of atypical chemokine receptors in inflammation and cancer'. The authors also regret that a mistake was made in Fig. 1. The corrected version can be found here. The authors would like to apologise for any inconvenience caused.

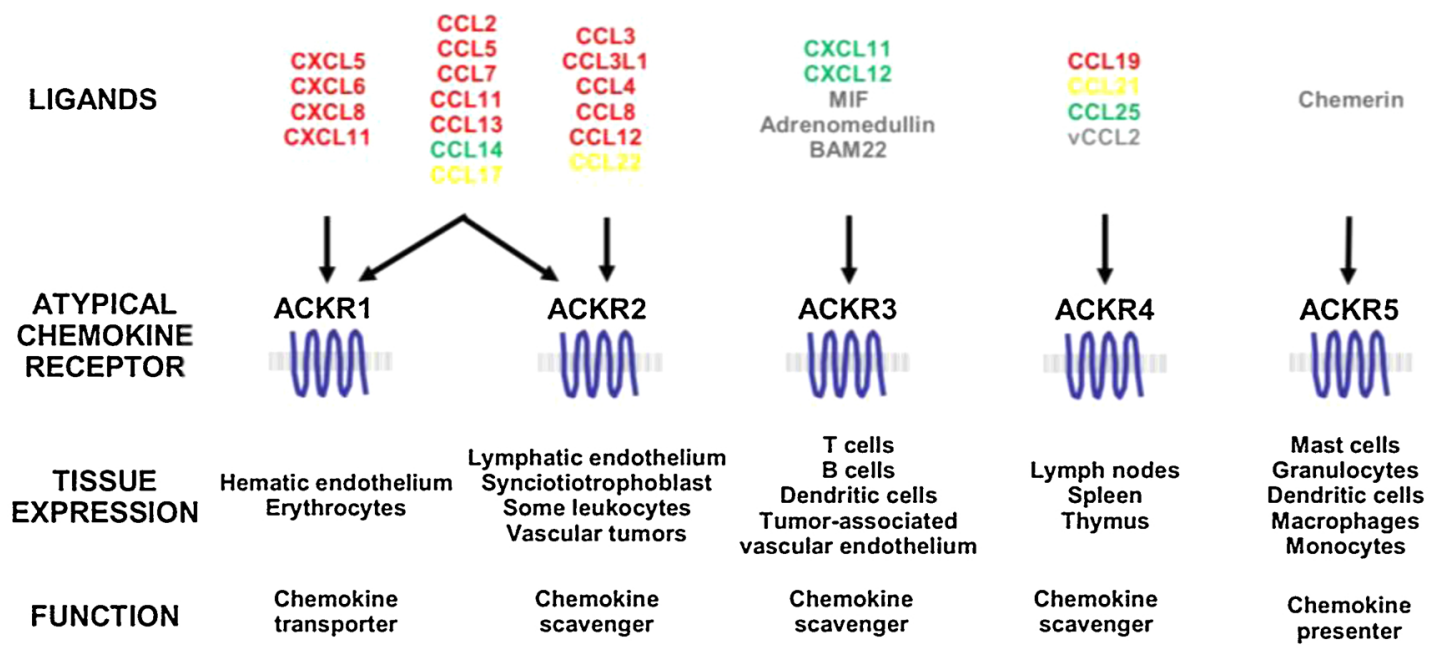

Figure 1. Atypical Chemokine Receptors: tissue distribution, ligand specificity, and biological functions.

Atypical Chemokine Receptors (ACKRs) recognize chemokines and control their distribution in tissues, thus operating as a prominent regulatory mechanisms of the chemokine system.

Chemokines are color-coded as pro-inflammatory (red), homeostatic (green) and mixed function (yellow). Non-chemokine ligands are reported in grey.

DOI of original article: https://doi.org/10.1016/j.smim.2018.10.005

* Corresponding author at: Humanitas Clinical and Research Center, Via Manzoni 113, 20089, Rozzano, Italy.

E-mail addresses: elena.borroni@unimi.it (E.M. Borroni), benedetta.savino@humanitasresearch.it (B. Savino), raffaella.bonecchi@humanitasresearch.it (R. Bonecchi), massimo.locati@humanitasresearch.it (M. Locati). 